\title{
Effect of two oil types and energy levels on broiler performance, carcass quality and skin pigmentation
}

\author{
Arturo Cortes-Cuevas ${ }^{\mathrm{a}^{*}}$, José L. Muñoz-Orozco ${ }^{\mathrm{a}}$, Gabriela G. Gómez-Verduzco ${ }^{\mathrm{b}}$, \\ Ernesto Ávila-González ${ }^{\mathrm{a}}$
}

\begin{abstract}
This study evaluated different levels of metabolisable energy (ME) and two oil types: crude soybean oil (CSO) and acidulated soybean oil (ASO), in sorghum-soybean meal diets for broilers. One thousand and eight unsexed Ross 308 chicks aged 1 to 49 days old were used in a factorial arrangement design $2 \times 3$. The first factor corresponded to the oils (CSO and ASO) and the second factor corresponded to the ME levels (high, medium and low) in the initiation (1-10 days), growing (11-25 days) and finishing (26-48 days) feeds, with a $90 \mathrm{kcal} / \mathrm{kg}$ reduction. The treatments were as follows: (1) CSO with 3010, 3175 and $3200 \mathrm{kcal} / \mathrm{kg}$; (2) CSO with 2920, 3085 and $3110 \mathrm{kcal} / \mathrm{kg}$; (3) CSO with 2920, 3085 and $3200 \mathrm{kcal} / \mathrm{kg}$; (4) ASO with 3010, 3175 and $3200 \mathrm{kcal} / \mathrm{kg}$; (5) ASO with 2920,3085 and $3110 \mathrm{kcal} / \mathrm{kg}$; and (6) ASO with 2920, 3085 and $3200 \mathrm{kcal} / \mathrm{kg}$. The treatments with high and medium levels of ME $(P<0.05)$ were higher. The carcass weight and skin pigmentation when cold were better in broilers fed with high and medium levels of ME $(P<0.05)$. No effect $(P>0.05)$ between oil types was found. It can be concluded that it is feasible to replace CSO by ASO and to reduce $90 \mathrm{kcal} / \mathrm{kg}$ of $\mathrm{ME}$ from the recommended amount for the breed during the initiation and growing stages, without affecting their performance.

Keywords: caloric restriction, broilers, productive performance, skin pigmentation.
\end{abstract}

\section{INTRODUCTION}

Metabolisable energy (ME) is considered the standard measure used to describe bird requirements. In diets offered to broilers, the ME plays an important role because it is used for catabolism, maintenance and production (Abudabus et al 2014, Sakomura et al 2014). Feeding programs are established based on ME requirements; therefore, nutritional strategies are sought in order to optimise productivity in the economic aspects during the production cycle (Andreoti et al 2004, Baião 2005).

The crude soybean oil (CSO) is used as a concentrated source of energy in balanced food for birds; however, due to its cost, several effective alternatives are sought such as lower-cost acidulated oils that have an acceptable nutritional quality (Barbour et al 2006, Carrillo 2013). The acidulated soybean oils (ASO) are by-products of the refining soybean oil process for human consumption. The disadvantage of this oil is its low quantity of linoleic acid, linolenic acid and total of polyunsaturated fatty acid when compared to CSO; however, ASO has a higher amount of total monounsaturated fatty acid and oleic (table 2). Also, ASO is cheaper than CSO.

During the process, free fatty acids (responsible for the acidity) are separated by the addition of $\mathrm{NaOH}$; subsequently,

\footnotetext{
Accepted: 07.09.2017.

a'Centro de Enseñanza, Investigación y Extensión en Producción Avícola, Facultad de Medicina Veterinaria y Zootecnia, Universidad Nacional Autónoma de México, Ciudad de México, México.

bDepartamento de Medicina y Zootecnia de Aves, Facultad de Medicina Veterinaria y Zootecnia, Universidad Nacional Autónoma de México, Ciudad de México, México.

*Corresponding author: A Cortes-Cuevas; Manuel M. López S/N, Col. Zapotitlán, CP. 13209, México; cortescuevasarturo@yahoo.com
}

they are separated using a decanting-centrifuging method and the resulting pastes are neutralised with sodium sulfuric acid. Finally, they are washed with abundant water in order to drag the excess of sulfuric acid, dried and cleaned by decantation (Cuca et al 2009). The ME level in the diet of broilers, is one of the main factors in the regulation of voluntary feed intake and feed conversion. According to Lesson and Summers (Leeson and Summers 2005), in ad libitum fed chickens the feed intake increases or decreases due to low or high ME levels in the diets.

The composition of fatty acid profile in oils is very important because it is has been shown that absorption of pigments (xantophyls) are better when the oils have unsaturated fatty acids. The mixture of polyunsaturated fatty acid and saturated fatty acid in oils, increases the absorption of lipids, improving the absorption of pigments (Fraser and Bramley 2004).

Therefore, another important parameter to consider is the skin pigmentation. It is well-known that appearance is one of the most important factors affecting the consumer's choice, and has been long recognised as a critical quality attribute for the marketing of chicken carcasses.

Feeding costs in birds have been increasing in recent years and the cost of energy is the most expensive nutrient on the diet (Cuca et al 2009). This requires finding specific and effective alternatives for having an adequate level of energy in broiler diets, without affecting production parameters and obtaining savings in diet formulation, that is the case of replacing the CSO by oil byproducts such as ASO, wich is $40-50 \%$ cheaper.

This experiment was designed to better understand the ME requirements and the feeding behaviour in Ross 308 chickens. Modern birds may present a good behaviour using low ME levels in diets, according to those levels recommended for the Ross 308 breed. Caloric restriction 
(90 $\mathrm{kcal} / \mathrm{kg}$ of ME) was studied, comparing to the Ross manual, in three different feed stages (0-10, 11-25 and 26-49 days of age), as well as the use of two oil types (crude soybean oil vs acidulated soybean oil) in order to reduce the cost of the diet and also evaluate broiler performance, carcass yield and skin pigmentation.

\section{MATERIAL AND METHODS}

The research was conducted at the Center for Teaching, Research and Outreach of Poultry Production (CEIEPAv.) of the Veterinary Medicine and Zootechnics Faculty, Universidad Nacional Autónoma de México. One thousand and eight mixed chickens from the Ross 308 breed, aged one day-old were divided into six treatments; each treatment had six repetitions with 28 birds. The birds were housed in 36 compartments or metal grid corrals. A completely randomised experimental design was used with a $2 \times 3$ factorial arrangement; the first factor was represented by the oils (Crude Soybean Oil (CSO) and Acidulated Soybean Oil (ASO), and the second factor corresponded to the three ME levels (high, medium and low) with a $90 \mathrm{kcal} / \mathrm{kg}$ reduction in the initiation, growing and finishing stages or only in the initiation and growing stages (table 1).

Sorghum + soybean meal diets were formulated for the three production stages: initiation (0-10 day-old), growing (11-25 day-old), and finishing (26-49 day-old), which covered all the nutrient recommendations (except for metabolisable energy) according to the Aviagen handbook guidelines for breed and production stage (table 2). The ASO was used in the diets as a replacement for CSO $(\mathrm{kg} / \mathrm{kg})$.

Prior to initiating the study, fatty acid profile analyses were performed in CSO and ASO samples following the procedures outlined by Carrillo-Dominguez (2013). The results of these analyses are shown in table 3 . Weight gain, feed intake, feed conversion, and mortality data were recorded. At the end of the study, two birds from each replicate of each treatment were sacrificed to determine carcass, breast and leg-thigh yields. Before slaughtering them, the birds were subjected to 8 hours of fasting and then weighed individually before hanging them on hooks for slaughtering poultry. They were desensitised using a commercial stunner under the perimeters of 25 volts, $0.25 \mathrm{amps}$ and $460 \mathrm{~Hz}$ of a direct pulsed type current. The slaughter was performed by unilateral neck cut in order to be bled out during 2 minutes. Immediately, they were scalded in a water tank at $53{ }^{\circ} \mathrm{C}$ for one minute, and then they were introduced into an automatic plucker. Evisceration was performed manually, circularly cutting the cloaca and making a second perpendicular cut to the cloaca cutting, to facilitate the removal of viscera. The gizzard, intestines, liver, heart, spleen and maw were extracted in order to finally obtain a rotisserie type carcass. The carcasses were weighed to calculate yield percentage, as well as breast and leg- thigh bone performances. Skin pigmentation (yellowness) was measured on the cold carcasses of ten birds (for each repetition per treatment) after processing, with a CR-400 Minolta reflectance colorimeter, on the lateral apteril region (vein's fatty).

The data obtained from the study variables were analysed under a completely randomised design with a factorial arrangement $2 \mathrm{X} 3$; first factor: two sources of oils and second factor: three levels of ME. The statistical differences between treatments were analysed through mean comparisons using a Tukey test, and considering a significance of $(P<0.05)$. The SPSS statistical package version 17 (SPSS 2010) was used for the statistical analysis.

\section{RESULTS}

The average results of the 1 to 21 days old chickens corresponding to weight gain, feed intake, feed conversion and mortality are shown in table 4 . It is possible to observe that there was no effect $(P>0.05)$ on the energy factor, however there was an effect on the oil factor regarding weight gain and food intake $(P<0.05)$.

Table 5 shows the average weight gain, feed intake, conversion and mortality data of the 1 to 49 day-old chickens for the energy and oil factors. Regarding the energy factor, a difference was observed between treatments $(P<0.05)$, where the birds fed with a high and medium ME amounts presented a higher weight gain compared to those fed with the lower ME amount. The low $\mathrm{ME}$ amount treatment obtained $6.6 \%$ and $6.3 \%$ less weight gain compared to the high and medium ME amount treatments.

Table 1. ME (kcal/kg) treatments for initiation, growing and finishing stages and energy sources.

\begin{tabular}{lccc}
\hline Treatment & Initiation & Growing & Finishing \\
\hline 1.- Diets 1, 3 and 5 with CSO high ME & 3010 & 3175 & 3200 \\
2.- Diets 2, 4 and 6 with CSO Medium ME & 2920 & 3085 & 3110 \\
3.- Diets 2, 4 and 5 with CSO low ME & 2920 & 3085 & 3200 \\
4.- Diets 1, 3 an 5 with ASO high ME & 3010 & 3175 & 3200 \\
5.- Diets 2, 4 and 6 with ASO Medium ME & 2920 & 3085 & 3110 \\
6.- Diets 2, 4 and 5 with ASO low ME & 2920 & 3085 & 3200 \\
\hline
\end{tabular}


Table 2. Composition of the experimental diets for broilers during initiation, growing and finishing, with different ME content.

\begin{tabular}{|c|c|c|c|c|c|c|}
\hline \multirow{2}{*}{$\frac{\text { Ingredient }}{\text { EM Diets }}$} & \multicolumn{2}{|c|}{ Initiation (kg) } & \multicolumn{2}{|c|}{ Growing (kg) } & \multicolumn{2}{|c|}{ Finishing (kg) } \\
\hline & 1 & 2 & 3 & 4 & 5 & 6 \\
\hline Sorghum & 540.133 & 561.155 & 544.084 & 565.132 & 603.184 & 623.647 \\
\hline Soybean paste & 375.793 & 371.633 & 354.025 & 349.859 & 294.813 & 291.288 \\
\hline ACS O AAS & 36.035 & 19.106 & 59.344 & 42.408 & 56.521 & 39.626 \\
\hline Orthophosphate & 18.536 & 18.482 & 16.281 & 16.228 & 15.107 & 15.05 \\
\hline Calcium carbonate & 15.334 & 15.361 & 13.856 & 13.883 & 13.344 & 13.371 \\
\hline Salt & 4.34 & 4.337 & 3.831 & 3.827 & 3.846 & 3.843 \\
\hline DL-methionine $99 \%$ & 2.204 & 2.19 & 3.193 & 3.179 & 1.494 & 1.486 \\
\hline L-Lysine $\mathrm{HCl}$ & 3.068 & 3.165 & 1.436 & 1.534 & 0.000 & 0.000 \\
\hline Vitamins* & 1.0 & 1.0 & 1.0 & 1.0 & 1.0 & 1.0 \\
\hline Minerals** & 1.0 & 1.0 & 1.0 & 1.0 & 1.0 & 1.0 \\
\hline Choline chloride $60 \%$ & 1.0 & 1.0 & 1.0 & 1.0 & 0.8 & 0.8 \\
\hline Coccidiostat $* * *$ & 0.5 & 0.5 & 0.5 & 0.5 & 0.5 & 0.5 \\
\hline Avelut pigment & 0.0 & 0.0 & 0.0 & 0.0 & 7.94 & 7.94 \\
\hline MD Bacitracin & 0.3 & 0.3 & 0.3 & 0.3 & 0.3 & 0.3 \\
\hline L-threonine & 0.607 & 0.62 & 0.0 & 0.0 & 0.0 & 0.0 \\
\hline Antioxidant & 0.15 & 0.15 & 0.15 & 0.15 & 0.15 & 0.15 \\
\hline Total & 1000 & 1000 & 1000 & 1000 & 1000 & \\
\hline Nutrient & \multicolumn{2}{|c|}{ CALCULATED ANALYSIS } & & & & \\
\hline Protein $\%$ & 23 & 23 & 22 & 22 & 19 & 19 \\
\hline Met+cist $\%$ & 0.99 & 0.99 & 0.90 & 0.90 & 0.83 & 0.83 \\
\hline Lysine $\%$ & 1.44 & 1.44 & 1.25 & 1.25 & 1.10 & 1.10 \\
\hline Calcium \% & 1.0 & 1.0 & 0.9 & 0.9 & 0.85 & 0.85 \\
\hline Phosphorus disp. \% & 0.5 & 0.5 & 0.45 & 0.45 & 0.42 & 0.42 \\
\hline EM (kcal/kg) & 3010 & 2920 & 3175 & 3085 & 3200 & 3110 \\
\hline
\end{tabular}

*Vitamin A (12,000,000 UI), vitamin D3 (2,500,000 UIP), vitamin E (15,000 UI), vitamin K (2.0g), vitamin B1 (2.25g), vitamin B2 (7.5g), vitamin B6 (3.5g), vitamin B12 (20mg), folic acid (1.5g), biotin (125mg), pantothenic acid (12.5g), niacin (45g); ${ }^{* *}$ Iron (50g), zinc (50g), manganese (110g), copper $(12 \mathrm{~g})$, iodine $(0.30 \mathrm{~g})$, selenium $(0.20 \mathrm{~g})$, Cobalt $(0.20 \mathrm{~g})$. Additional amounts of vitamins and minerals per ton of feed.

*** Nicarbazin during initiation and growth, and Monensin for conclusion.

Feed conversion results for the oil factor showed a difference between oils $(P<0.05)$, with a better conversion in the animals treated with crude soybean oil than those treated with acidulated oil; however, there was no difference in weight gain, consumption and mortality.

Regarding the carcass and breast and leg-thigh performances, no significant differences were observed in the factors $(P<0.05)$. However, for the energy factor there was a difference $(P<0.05)$, because skin pigmentation was lower (less yellowness for 2 points) in birds fed lower ME diets. In contrast for the oil factor, there was no difference between the two oils $(P<0.05)$, data can be seen in table 6 .

\section{DISCUSSION}

The energy factor influenced weight gain because low ME diets had a lower weight gain and carcass yield in comparison to birds fed high and medium energy diets; even the latter had similar results. These results were similar to those found by Andreotti et al 2004, who attributed this effect to the increased consumption of ME.

This data partly agrees with the reports of Skinner et al (1993), who did not find any energy effect on the productive performance of broilers when they used two levels of ME for three production stages, and observed that there was not any significant alteration of the energy diet on the productive performance of 49 day-old birds. Similar results were also obtained in an experiment conducted by Hidalgo et al (2004), who did not found any differences in weight gain and feed conversion when the diet ME decreased from 3196 to $3020 \mathrm{Kcal} / \mathrm{kg}$. Furthermore, Lopez et al 2011, did not find any significant differences for the $90 \mathrm{kcal} / \mathrm{kg}$ reduction in the initiation and growing diets. However, the production parameters were significantly affected due to the caloric restriction in the diet during the completion stage.

On the other hand, Sizemore and Sigel (1993) reported a better growing and feed conversion at the completion 
Table 3. Fatty acid profile for crude and acidulated soybean oils.

\begin{tabular}{lcc}
\hline Fatty Acid (\%) & CSO & ASO \\
\hline Linoleic acid (LA) (C18:2) & $51.09 \pm 0.42$ & $28.01 \pm 0.3$ \\
Alpha-linolenic (ALA) (C18:3) & $7.52 \pm 0.1$ & $6.59 \pm 0.11$ \\
Eicosenoic (C20:1) & $0.23 \pm 0.03$ & $0.82 \pm 0.12$ \\
Eicosapentaenoic (EPA) (C20:5) & $0.36 \pm 0.01$ & $\mathrm{ND}$ \\
Myristic (C14:0) & $0.11 \pm 0.01$ & $0.47 \pm 0.03$ \\
Palmitic (C16:0) & $11.74 \pm 0.14$ & $11.62 \pm 0.17$ \\
Palmitelaidic (C16:1TRANS) & $\mathrm{ND}$ & $0.29 \pm 0.29$ \\
Palmitoleic (C16:1) & $0.18 \pm 0.1$ & $0.33 \pm 0.03$ \\
Heptadecanoic (C17:0) & $0.11 \pm 0.01$ & $0.14 \pm 0.01$ \\
CIS 10- Heptadecanoic (C17:1) & $\mathrm{ND}$ & $\mathrm{ND}$ \\
Stearic (C18:0) & $4.17 \pm 0.24$ & $3.34 \pm 0.18$ \\
Elaidic (C18:1 TRANS) & $\mathrm{ND}$ & $43.13 \pm 0.01$ \\
Oleic (C18:1) & $22.3 \pm 2.22$ & $1.42 \pm 0.3$ \\
CIS- Vaccenic (C18:1) & $0.87 \pm 0.2$ & $28.01 \pm 0.3$ \\
Linolenic acid (LA) (C18:2) & $51.09 \pm 0.42$ & $6.59 \pm 0.11$ \\
Alpha-lonolenic (ALA) (C18:3) & $7.52 \pm 0.1$ & $\mathrm{ND}$ \\
Arachidonic (C20:1) & $0.32 \pm 0.02$ & $0.82 \pm 0.12$ \\
Eicosenoic (20:1) & $0.23 \pm 0.03$ & $\mathrm{ND}$ \\
Eicosapentaenoic (EPA) (C20:5) & $0.36 \pm 0.01$ & 0.94 \\
Other fatty acids & 0.86 & 16.97 \\
Total of saturated (\%) & 16.5 & 47.17 \\
Total of monounsaturated (\%) & 23.67 & 34.92 \\
Total of polyunsaturated (\%) & 58.97 & \\
\hline
\end{tabular}

Table 4. Productive parameters in 1 to 21 day-old broilers fed with ME different levels (High, Medium and Low) and sources (crude soybean oil and acidulated soybean oil) of energy.

\begin{tabular}{|c|c|c|c|c|}
\hline Factors & Weight gain (g) & Feed intake (g) & Feed conversion & Mortality (\%) \\
\hline \multicolumn{5}{|l|}{ Energy } \\
\hline High & $698 \pm 9.9 a$ & $1172 \pm 14 \mathrm{a}$ & $1.68 \pm .01 \mathrm{a}$ & $2.0 \pm 0.2 \mathrm{a}$ \\
\hline Medium & $714 \pm 9.9 a$ & $1196 \pm 14 a$ & $1.67 \pm .01 \mathrm{a}$ & $1.5 \pm 0.2 \mathrm{a}$ \\
\hline Low & $710 \pm 9.9^{\mathrm{a}}$ & $1189 \pm 14 a$ & $1.67 \pm 01 \mathrm{a}$ & $2.0 \pm 0.2 \mathrm{a}$ \\
\hline Probability & 0.458 & 0.483 & 0.907 & 0.681 \\
\hline \multicolumn{5}{|l|}{ Soybean oil } \\
\hline Crude & $720 \pm 8 a$ & $1210 \pm 8 \mathrm{a}$ & $1.68 \pm .01 \mathrm{a}$ & $2.2 \pm 0.8 \mathrm{a}$ \\
\hline Acidulated & $695 \pm b$ & $1162 \pm 8 b$ & $1.67 \pm .01 \mathrm{a}$ & $1.6 \pm 0.8 \mathrm{a}$ \\
\hline Probability & 0.035 & 0.007 & 0.549 & 0.506 \\
\hline
\end{tabular}

Values with different letters are statistically different (see probability).

stage in chickens fed with high ME diets (3190 kcal/kg). However, Pardío et al (2001) evaluated acidulated oils from different sources, finding that acidified soybean oil had a better weight gain response in birds fed during 1 to 7 weeks, indicating that the use of this acidulated oil is a viable alternative for feeding broilers.

Baião (2005), recommends the use of acidified soybean oil as a substitute for vegetable oil, as a source of polyunsaturated fatty acids. However, other authors note that this energetic ingredient has a $10 \%$ lower energy value of ME on average (Sizemore and Siegel (1993).

The ME factor data showed a higher weight gain and carcass weight gain in birds fed high and medium ME amounts; these results agree somewhat with those reported by Barbour et al (2006), who conducted an experiment with broilers where the ME levels were $3.3 \%$, using two 
Table 5. Productive performance in 1 to 49 day-old broilers fed with ME different levels (High, Medium and Low) and sources (crude soybean oil and acidulated soybean oil) of energy.

\begin{tabular}{lcccc}
\hline Factors & Weight gain $(\mathrm{g})$ & Feed intake $(\mathrm{g})$ & Feed conversion & Mortality $(\%)$ \\
\hline Energy & & & & \\
High & $3138 \pm 48 \mathrm{a}$ & $6522 \pm 75 \mathrm{a}$ & $2.1 \pm .03 \mathrm{a}$ & $6.5 \pm 1.34 \mathrm{a}$ \\
Medium & $3125 \pm 48 \mathrm{a}$ & $6552 \pm 75 \mathrm{a}$ & $2.1 \pm .03 \mathrm{a}$ & $4.7 \pm 1.34 \mathrm{a}$ \\
Low & $2930 \pm 48 \mathrm{~b}$ & $6482 \pm 75 \mathrm{a}$ & $2.2 \pm 03 \mathrm{~b}$ & $6.8 \pm 1.34 \mathrm{a}$ \\
Probability & 0.008 & 0.805 & 0.017 & 0.560 \\
\hline Soybean oil & & & & \\
\hline Crude & $311539 \mathrm{a}$ & $6476 \pm 61 \mathrm{a}$ & $2.1 \pm .03 \mathrm{a}$ & $6.7 \pm 1.09 \mathrm{a}$ \\
Acidulated & $301539 \mathrm{a}$ & $6570 \pm 61 \mathrm{a}$ & $2.2 \pm .03 \mathrm{~b}$ & $5.3 \pm 1.09 \mathrm{a}$ \\
Probability & 0.082 & 0.248 & 0.01 & 0.578 \\
\hline
\end{tabular}

Values with different letters are statistically different (see probability).

Table 6. Average performance data of the carcass and body-parts (breast and thigh-leg performance, and yellowness of the skin) on 1 to 49 day-old broilers.

\begin{tabular}{|c|c|c|c|c|}
\hline Factors & $\begin{array}{c}\text { Carcass performance } \\
(\%)\end{array}$ & $\begin{array}{l}\text { Breast performance } \\
(\%)\end{array}$ & $\begin{array}{l}\text { Thigh-leg performance } \\
\qquad(\%)\end{array}$ & $\begin{array}{l}\text { Yellowness } \\
\text { of the skin (b) }\end{array}$ \\
\hline \multicolumn{5}{|l|}{ Energy } \\
\hline High & $72 \pm .6 a$ & $40 \pm 1 \mathrm{a}$ & $31 \pm .8^{\mathrm{a}}$ & $43 \pm .4 a$ \\
\hline Medium & $72 \pm .6 a$ & $38 \pm 1 a$ & $30 \pm .8^{\mathrm{a}}$ & $43 \pm .4 a$ \\
\hline Low & $73 \pm .6 a$ & $37 \pm 1 a$ & $31 \pm .8 \mathrm{a}$ & $41 \pm .4 b$ \\
\hline Probability & 0.22 & 0.265 & 0.691 & 0.007 \\
\hline \multicolumn{5}{|l|}{ Soybean oil } \\
\hline Crude & $73 \pm .5 a$ & $39 \pm .8 \mathrm{a}$ & $31 \pm .6 a$ & $42 \pm .3 a$ \\
\hline Acidulated & $72 \pm .5 a$ & $38 \pm .8 \mathrm{a}$ & $31 \pm .6 a$ & $42 \pm .3 a$ \\
\hline Probability & 0.313 & 0.37 & 0.805 & 0.997 \\
\hline
\end{tabular}

Values with different letters are statistically different (see probability).

production stages only (0-21 and 22-49). The results indicated a growth improvement in birds fed a high energy level diet. They also emphasised that the differences between treatments were more evident in the second feed stage in comparison to the first; these evidences coincided with our results, since the most noticeable differences occurred during the last production stage.

Regarding consumption, no treatment differences were found which contrasts with the research of Dozier et al (2006), who observed that the consumption decreased proportionally (falling 5.2\%), by decreasing the energy content of the ration, from $3383 \mathrm{Kcal} / \mathrm{kg}$ to $3023 \mathrm{Kcal} / \mathrm{kg}$. The different results can be explained by the ME amount in diets because in the present work the ME was reduced $90 \mathrm{kcal}$ in each phase, whereas in the study of Dozier et al (2007), they observed a $10 \%$ reduction, which also affected other production parameters (e.g. body weight).

Our results also differ from those obtained by Leeson et al (1996) and Lara et al (2008) who found a consumption decrease as the dietary energy level increased, highlighting that the bird is capable of regulating the consumption. During this study, this regulation might not have occurred because the ME reduction was $90 \mathrm{kcal} / \mathrm{kg}$ only.

In the study performed by Dozier et al (2007), two ME levels were used. The first level contained $3220 \mathrm{Kcal} / \mathrm{kg}$, whereas the second level contained a higher contribution of $\mathrm{ME}(3310 \mathrm{Kcal} / \mathrm{kg})$. The results showed that the ME decreased in $2.9 \%$, and the consumption and growth parameters did not change significantly between treatments. Also, feed conversion was influenced by the ME amount, since the birds treated with lower amounts of energy were $4.6 \%$ less efficient than those fed with medium and high energy amounts. Therefore, the results of this study agree with Lesson and Summers (2005), who indicated that birds fed with high ME levels obtained a higher feed efficiency.

It can be concluded that both chicken and carcass weight, and skin pigmentation decreased by reducing 90 $\mathrm{kcal} / \mathrm{kg}$ of ME during the initiation, growing and completion stages. The use of acidulated soybean oil proved to be an alternative for crude soybean oil in broiler chicken 
diets in order to reduce the cost of diet. Finally, it is possible to feed the chickens with reduced ME diets during the initiation and growing stages, without affecting the productive performance, carcass and skin pigmentation.

\section{REFERENCES}

Abudabus AM, Saleh F, Lemme A, Zakaria HAH. 2014. The relationship between guanidine acetic acid and metabolizable energy level of diets on performance of broiler chickens. Italian J Anim Sci 13, 548-556.

Andreotti M, Junqueira O, Barbosa M, Cancherini L, Araújo L, et al. 2004. Energia metabolizável do óleo de soja em diferentes níveis de inclusão para frangos de corte nas fases de crescimento e final. Rev Soc Bras Zoot 33, 1145-1151.

Baião NC. 2005. Oil and fat in broiler nutrition. Brazilian J Poult Sci 7, 129-141.

Barbour GW, Farran MT, Usayran NN, Darwish AH, Uwayjan MG, et al. 2006. Effect of soybean oil supplementation to low metabolizable energy diets on production parameters of broiler chickens. J Appl Poult Res 15, 190-197.

Carrillo S. 2013. Alternativas para incrementar la estabilidad oxidativa en huevo para plato enriquecido con ácidos grasos omega-3. Tesis Doctorado, Universidad Nacional Autónoma de México, Ciudad de México, México.

Cuca GM, Ávila GE, Pro MA. 2009. Alimentación de las aves. $2^{\mathrm{a}} \mathrm{ed}$. Universidad Autónoma de Chapingo, Estado de México, México.

Dozier WA III, Price CJ, Kidd MT, Corzo A, Anderson J, et al. 2006 Growth performance, meat yield, and economic responses of Ross $\times$ Ross 308 broilers provided diets varying in metabolizable energy from 30 to 59 days of age during low and moderate temperatures. J Appl Poult Res 15, 383-393.

Dozier WA III, Purswell JL, Kidd MT, Corzo A, Branton SL. 2007. Apparent metabolizable energy needs of broilers from 2.0 to
$4.0 \mathrm{~kg}$ as influenced by ambient temperature. J Appl Poult Res 16 , 206-218.

Fraser P, Bramley P. 2004. The biosynthesis and nutritional uses of carotenoids. Prog Lipid Res 43, 228-265.

Hidalgo MA, Dozier WA III, Davis AJ, Gordon RW. 2004. Live performance and meat yield responses of broilers to progressive concentrations of dietary energy maintained at a constant metabolizable energy to crude protein ratio J App Poult Res 13, 319-327.

Lara JCL, Teixeira JL, Baião NC, Cançado SV, Rocha JSR, et al. 2008. Efeito dos níveis de energia da dieta sobre o desempenho e rendimentos de carcaça de frangos de corte. Revista Ceres 55, 402-408.

Leeson S, Caston L, Summers JD. 1996. Broiler response to diet energy. Poult Sci 75, 529-535.

Leeson S, JD Summers. 2005. Commercial Poultry Nutrition. University of Guelph, Guelph, Canada, Pp 230-237.

López OL, Cortés CA, Ávila GE. 2011. Respuesta productiva en pollos Ross 308 alimentados con dietas sorgo-soya con y sin restricción calórica. $X X X V$ Convención Nacional ANECA, Ixtapa Zihuatanejo, Jalisco, México, Pp 66-69.

Pardio VT, Landin LA, Waliszewski KN, Badillo C, Perez-Gil F. 2001. The effect of acidified soapstocks on feed conversion and broiler skin pigmentation. Poult Sci 80, 1236-1239.

Sakomura NK, Hauschild L, Bonato MA. 2014. Modelagem da utilizacao da energia nas aves. Nutricao de nao ruminates 13, 313-329.

Sizemore FG, Siegel HS. 1993. Growth, feed conversion, and carcass composition in females of four broiler crosses fed starter diets with different energy levels and energy to protein ratios. Poult Sci 72, 2216-2228.

Skinner JT, Cabel MC, Waldroup AL. 1993. Effects of abrupt and multiple changes in dietary nutrient density on performance of broilers. J Appl Poult Res 2, 33-39.

SPSS, Statistical Package for Social Sciences. 2010. SPSS version 17.0. SPSS Inc., Chicago, USA. 